\section{Pyruvate Kinase and the "High ATP Syndrome"}

G. E. J. Staal, G. Jansen, and D. Roos

Department of Hematology, Division of Medical Enzymology, Academic Hospital Utrecht, 3500 CG Utrecht, The Netherlands; Central Laboratory of the Netherlands Red Cross Blood

Transfusion Service, Amsterdam, The Netherlands
A the so-called "high ATP syndrome" were characterized by a high ATP content and low 2,3-diphosphoglycerate level. The pyruvate kinase activity was specifically increased (about twice the normal level). After separation of the erythrocytes according to age by discontinuous Percoll density centrifugation, the pyruvate kinase activity was found to be increased in all Percoll fractions. Pyruvate kinase of the patient's cells was characterized by a decreased $K_{0.5}$ for the substrate phosphoenolpyruvate and no inhibition by ATP. The Michaelis constant $\left(K_{\mathrm{m}}\right)$ value for ADP, the nucleotide specificity, the thermostability, pH optimum, and immunological specific activity were normal. It is concluded that the high pyruvate kinase activity is due to a shift in the $\mathrm{R}$ (elaxed) $\rightleftharpoons \mathrm{T}$ (ight) equilibrium to the $\mathbf{R}$ (elaxed) form.

\section{Introduction}

Pyruvate kinase (ATP: pyruvate phosphotransferase, EC 2.7.1.40) catalyzes the conversion of phosphoenolpyruvate to pyruvate, with the generation of ATP. Three isozymes are known of pyruvate kinase, which are designated as liver $(\mathrm{L}),{ }^{1}$ muscle (M), and kidney (K) type, the latter also termed $\mathrm{M}_{2}(1)$. Human erythrocyte pyruvate kinase is closely related to the liver-type pyruvate kinase (2). In erythroid precursor cells, the tetrameric enzyme is synthesized as an active precursor, designated $L_{4}^{\prime}$,

Address all correspondence to Dr. Staal, Department of Hematology, Division of Medical Enzymology, Academic Hospital Utrecht, 3500 CG Utrecht, The Netherlands.

Received for publication 29 December 1983 and in revised form 15 March 1984

1. Abbreviations used in this paper: 2,3-DPG, 2,3-diphosphoglycerate; HPLC, high pressure liquid chromatography; K, kidney; L, liver; $M$, muscle; $R$, relaxed; $T$, tight.

\footnotetext{
J. Clin. Invest.

(c) The American Society for Clinical Investigation, Inc. 0021-9738/84/07/0231/05 $\$ 1.00$

Volume 74, July 1984, 231-235
}

which is partially proteolyzed to $\mathrm{L}_{2}^{\prime} \mathrm{L}_{2}$, the predominant form in the mature erythrocyte (3). Hereditary nonspherocytic hemolytic anemia due to a pyruvate kinase abnormality was first described by Valentine et al. (4), and more than 300 cases have been reported since then. Pyruvate kinase deficiency results in a diminished capacity to regenerate ATP, and the content of 2,3-diphosphoglycerate (2,3-DPG) may be increased.

A hereditary increase of erythrocyte ATP has been described only in a few cases ("high ATP syndrome"). Brewer $(5,6)$ reported the occurrence of a hereditary abnormality that was characterized by significantly increased ATP content, normal pyruvate kinase activity, and no signs of hemolysis. High erythrocyte ATP has also been reported to coexist with a erythrocyte 2,3-DPG phosphatase deficiency (7). Recently, a family was described (8) in which polycythemia and erythrocyte abnormalities occurred. Members of this family displayed high pyruvate kinase activity associated with high ATP and low 2,3DPG levels, but all other erythrocyte enzyme activities tested were normal. Zürcher et al. (9) have described a family with an abnormality characterized by high erythrocyte ATP (180$200 \%$ of the normal value), increased pyruvate kinase activity (about twice the normal level), normal lactate production, and decreased 2,3-DPG content. The mode of inheritance was autosomal dominant; no hemolysis was observed. The marked increase in pyruvate kinase activity was believed to be responsible for the high ATP, but no characterization of the pyruvate kinase was performed. This paper describes a reinvestigation of the abnormality described by Zürcher et al. (9). We have confirmed the earlier findings reported in Ref. 8. Furthermore, characterization of this pyruvate kinase showed that the high activity is due to a shift in the relaxed $(R) \rightleftharpoons$ tight $(T)$ equilibrium to the R state.

\section{Methods}

Substrates, coenzymes, and auxilliary enzymes for determination of glycolytic enzymes and intermediates, except for the determination of 2,3-DPG, were obtained from Boehringer (Mannheim, Federal Republic of Germany).

Venous blood was collected in heparin $(30 \mathrm{U} / \mathrm{ml})$. Immediately after collection, part of the blood was deproteinized for the determination of glycolytic intermediates. Deproteinization and determination of all glycolytic intermediates except 2,3-DPG were performed according to Minakami et al. (10). The 2,3-DPG content of the acid extract was determined 
with a test kit (Sigma Technical Bulletin 35-UV, Sigma Chemical Co., St. Louis, MO). Erythrocytes were isolated by filtration of whole blood through an $\alpha$-cellulose-crystalline cellulose mixture (11).

The erythrocyte glycolytic enzymes were determined by the methods of Beutler (12). Kinetic studies of pyruvate kinase were performed as recommended by the International Committee for Standardization in Haematology (13). Trypsin treatment of pyruvate kinase was performed as described by Kahn et al. (3). Rabbit antisera against human pyruvate kinase-L were a generous gift from Dr. A. Kahn (Institut de Pathologie Moléculaire, Paris). Nucleotides in neutralized perchloric acid extracts of purified erythrocytes were separated with an anion-exchange high pressure liquid chromatography (HPLC) method essentially as described by McKeag and Brown (14).

Separation of erythrocytes in four fractions of different ages was achieved by using a discontinuous Percoll density gradient, prepared as described by Rennie et al. (15). $1.5 \mathrm{ml}$ of erythrocytes (hematocrit 20\%) were layered onto gradients comprising 5-ml layers of $80,72,65,58$, and $40 \%$ Percoll $/ 5 \%$ bovine serum albumin and were centrifuged at $1000 \mathrm{~g}$ for $15 \mathrm{~min}$ in a swing out rotor. The cells were freed of Percoll by three washes in phosphate-buffered saline.

Mononuclear leukocytes and granulocytes were purified as described previously (16). Granulocyte functions were tested as described (16).

Patient. The proband, a healthy man, showed no signs of hemolysis. Routine hematological data were completely normal (Table I).

\section{Results}

\section{Erythrocytes}

Enzyme activity. Pyruvate kinase activity of the erythrocytes of the patient was about twice the normal level; all other tested erythrocytic enzyme activities were normal (Table II). Table III shows the age dependency of hexokinase, glucose-6-phosphate dehydrogenase, and pyruvate kinase activities of the patient and controls after separation of the erythrocytes according to age by discontinuous Percoll density gradient centrifugation. Compared with normal values, the pyruvate kinase activity of the patient in the $58,65,72$, and $80 \%$ Percoll fractions was considerably increased. The cellular distribution of the patient's erythrocytes over the gradient was normal (Table III).

Glycolytic intermediates. The contents of glycolytic inter-

Table I. Some Routine Hematological Data of the Patient

\begin{tabular}{lcc}
\hline & Patient & Normals \\
\hline Erythrocytes $\left(\times 10^{12} /\right.$ liter $)$ & 5.05 & $4.1-5.6$ \\
Hemoglobin $(g / d l)$ & 15.1 & $13.8-17.6$ \\
Hemoglobin subtype & AA & AA \\
Hemoglobin $\mathrm{A}_{2}(\%)$ & 2.8 & $1.9-3.0$ \\
Hemoglobin $\mathrm{F}(\%)$ & 0.5 & $0.1-1.5$ \\
Packed cell volume $(\mathrm{ml} / 100 \mathrm{ml})$ & 50 & $41-51$ \\
Mean corpuscular volume $(f l)$ & 99 & $84-104$ \\
Mean corpuscular hemoglobin $(p g)$ & 32 & $28-36$ \\
Mean corpuscular hemoglobin concentration & & \\
$\quad(g / 100$ ml erythrocytes $)$ & 32 & $32-37$ \\
Reticulocytes $(\%)$ & 0.5 & $0.4-1.8$ \\
Leukocytes $\left(\times 10^{9} /\right.$ liter $)$ & 6.9 & $4-10$ \\
\end{tabular}

Table II. Erythrocyte Enzyme Activities

\begin{tabular}{lcc}
\hline & $\begin{array}{c}\text { Patient } \\
\mathrm{U} / \mathrm{gHb}\end{array}$ & $\begin{array}{l}\text { Normal controls } \\
\text { mean } \pm \mathrm{SD}(n=50) \\
\mathrm{U} / \mathrm{gHb}\end{array}$ \\
\hline Hexokinase & 1.05 & $1.15 \pm 0.35$ \\
Phosphoglucose isomerase & 65.9 & $67.7 \pm 12.0$ \\
6-Phosphofructokinase & 9.0 & $8.4 \pm 3.4$ \\
Aldolase & 3.3 & $3.55 \pm 1.07$ \\
Triosephosphate isomerase & 2,584 & $2,700 \pm 700$ \\
Glyceraldehyde dehydrogenase & 73.4 & $79 \pm 56$ \\
Phosphoglycerate kinase & 253 & $312 \pm 86$ \\
Diphosphoglycerate mutase & 6.5 & $5.3 \pm 2.5$ \\
Enolase & 7.8 & $7.8 \pm 2.2$ \\
Pyruvate kinase & 23.0 & $11.4 \pm 2.8$ \\
Glucose-6-P dehydrogenase & 11.7 & $10.9 \pm 3.8$ \\
6-P-gluconate dehydrogenase & 9.6 & $8.4 \pm 1.0$ \\
Glutathione reductase & 6.2 & $7.2 \pm 2.2$ \\
& &
\end{tabular}

mediates of the patient's erythrocytes are shown in Table IV. The 2,3-DPG level in the patient's erythrocytes was strongly decreased, whereas the content of ATP was increased about twice. The levels of 2-P-glycerate, 3-P-glycerate, and 2-P-enolpyruvate were in the low normal range. The content of fructose1,6-diphosphate was normal. HPLC analysis proved that ADP and AMP were normal; ATP, GTP, and IMP were increased (Table V).

Characterization of pyruvate kinase. Pyruvate kinase characterization was performed on partially purified enzyme preparations, as recommended by the International Committee for Standardization in Haematology (13). The results are presented in Table VI.

Pyruvate kinase of the patient's erythrocytes was characterized by a decreased $K_{0.5}$ for the substrate P-enol-pyruvate (more than sixfold decreased compared with controls) and a decreased Hill coefficient. Much less activation was observed with Fru-1,6- $\mathrm{P}_{2}$, the positive effector of pyruvate kinase (compared with the enzyme of controls). The Michaelis constant $\left(K_{m}\right)$ value for ADP, the nucleotide specificity, the thermostability, and pH optimum were normal. The enzyme was not inhibited by ATP (under the conditions tested). Electrophoresis of the patient's enzyme both in the presence and absence of trypsin showed an identical pattern with those of the controls. The immunological specific activity defined as the number of enzyme units precipitated by $1 \mathrm{ml}$ of antiserum was normal.

\section{Leukocytes}

Mononuclear leukocytes and granulocytes of the patient had normal activities of pyruvate kinase and normal nucleotide contents. The respiratory burst, the viability during incubation with phorbolmyristate acetate, and the killing of Escherichia coli by the granulocytes of the patient was also normal (results not shown). 
Table III. Erythrocyte Activities of Hexokinase, Glucose-6-P Dehydrogenase, and Pyruvate Kinase in Four Age-separated Fractions for Controls and Propositus

\begin{tabular}{|c|c|c|c|c|c|}
\hline \multirow[b]{2}{*}{ Age-dependent separation } & \multicolumn{5}{|l|}{ Percoll } \\
\hline & 0 & $58 \%$ & $65 \%$ & $72 \%$ & $80 \%$ \\
\hline \multicolumn{6}{|l|}{ Controls $(n=6)$} \\
\hline Hexokinase & $1.17 \pm 0.19$ & $2.61 \pm 1.6$ & $1.55 \pm 0.30$ & $1.16 \pm 0.16$ & $0.94 \pm 0.20$ \\
\hline Glucose-6-P dehydrogenase & $13.7 \pm 1.0$ & $19.5 \pm 8.0$ & $15.7 \pm 1.5$ & $13.2 \pm 1.5$ & $9.8 \pm 0.9$ \\
\hline Pyruvate kinase & $12.6 \pm 1.6$ & $22.8 \pm 3.7$ & $15.6 \pm 2.4$ & $11.5 \pm 1.7$ & $9.5 \pm 1.9$ \\
\hline \multicolumn{6}{|l|}{ Propositus } \\
\hline Hexokinase & 1.33 & 2.91 & 1.46 & 1.16 & 0.79 \\
\hline Glucose-6-P dehydrogenase & 13.3 & 19.2 & 14.4 & 12.6 & 10.1 \\
\hline Pyruvate kinase & 20.1 & 27.8 & 22.5 & 17.4 & 16.3 \\
\hline \multicolumn{6}{|l|}{ Cellular distribution (\%) } \\
\hline Controls $(n=12)$ & & $1.8 \pm 0.6$ & $33.4 \pm 15.0$ & $58.4 \pm 13.0$ & $6.4 \pm 6.2$ \\
\hline Propositus & & 1 & 38 & 55 & 6 \\
\hline
\end{tabular}

The enzyme activities (IU/g Hb) of the unseparated samples (0) and the $58,65,72$, and $80 \%$ Percoll fractions, respectively, are expressed as mean \pm SD.

\section{Discussion}

The patient presented in this paper has already been reported by Zürcher et al. (9). We confirmed earlier findings: erythrocyte pyruvate kinase activity was increased, whereas all other erythrocyte enzyme activities, including diphosphoglycerate mutase, were normal (Table II). The high pyruvate kinase activity was not related to an elevated reticulocyte count. This is clearly illustrated in Table III; after separation according to age by discontinuous Percoll density gradient centrifugation, pyruvate kinase activity was specifically increased in the different fractions. In contrast, normal values were found for the age-dependent enzymes, hexokinase and glucose-6-phosphate dehydrogenase. Also, the cellular distribution of the patient's erythrocytes over the gradient was normal (Table III).

The high pyruvate kinase activity was accompanied by a

Table IV. Erythrocyte Glycolytic Intermediates

\begin{tabular}{lcc}
\hline & Patient & Normals $(n=20)$ \\
\hline Fructose-1,6-diphosphate & 5.4 & $5.1 \pm 1.7$ \\
2,3-Diphosphoglycerate & 700 & $4,800 \pm 300$ \\
3-P-Glycerate & 29 & $55 \pm 35$ \\
2-P-Glycerate & 4.1 & $9.1 \pm 5.3$ \\
2-P-enol pyruvate & 7.8 & $13.4 \pm 8.0$ \\
Pyruvate & 72 & $125 \pm 75$ \\
ATP & 2,500 & $1,300 \pm 250$ \\
\end{tabular}

Concentrations are expressed in nanomoles per milliliter of erythrocytes, except for pyruvate (nanomoles per milliliter of blood). very low 2,3-DPG level and a high content of ATP in the erythrocytes. Despite the very low 2,3-DPG content, there was no pronounced erythrocytosis: the number of erythrocytes was in the normal range. The same association between high pyruvate kinase activity and a low level of 2,3-DPG has been reported by Rosa et al. (17) in four members of a family, and has also been shown in rabbit erythrocytes during ontogeny by Jelkmann and Bauer (18). The high pyruvate kinase activity seems to favor the Embden-Meyerhof pathway and ATP synthesis, whereas the 2,3-DPG synthesis is at a disadvantage.

It has been hypothesized by Zürcher et al. (9) that a high pyruvate kinase activity will result in a low concentration of 2-phospho-enol-pyruvate, and consequently, 2-phosphoglycerate and 3-phosphoglycerate will be low too. The low values of these

Table V. HPLC Analysis of Nucleotides in Purified Erythrocytes

\begin{tabular}{lccc}
\hline & Propositus & $\begin{array}{c}\text { Controls }(n=7) \\
\text { mean } \pm \text { SD }\end{array}$ & Range \\
\hline Inosine monophosphate & 6 & $2 \pm 0.8$ & $0.7-3.1$ \\
AMP & 1 & $2 \pm 0.2$ & $1.7-2.3$ \\
ADP & 12 & $22 \pm 7$ & $12-29$ \\
ATP & 185 & $119 \pm 16$ & $95-1.36$ \\
Guanosine diphosphate & 0.9 & $1 \pm 0.3$ & $0.7-1.5$ \\
Guanosine triphosphate & 7 & $3 \pm 1$ & $1.4-4.3$ \\
UDP glucose & 3 & $5 \pm 1.6$ & $3-7$ \\
UDP-N-acetylgalactosamine & 0.6 & $0.3 \pm 0.1$ & $0.2-0.5$ \\
& & &
\end{tabular}

Values in pmol $/ 10^{6}$ erythrocytes. Guanosine monophosphate, UDP, uridine triphosphate, cytidine monophosphate, cytidine diphosphate, and cytidine triphosphate were not detectable in the patient's cells and $<1 \mathrm{pmol} / 10^{6}$ normal erythrocytes. 
Table VI. Properties of Pyruvate Kinase of the Propositus and Controls

\begin{tabular}{|c|c|c|}
\hline & Propositus & Controls, mean \pm SD \\
\hline Enzyme activity $(I U / g H b)$ & 20.1 & $12.6 \pm 1.6 \quad(n=10)$ \\
\hline $\mathrm{K}_{0.5}$ P-enol-pyruvate $(m M)$ & 0.15 & $0.93 \pm 0.06(n=15)$ \\
\hline$n$-Hill & 1.1 & $2.2 \pm 0.2 \quad(n=15)$ \\
\hline $\begin{array}{l}\mathrm{K}_{0.5} \text { P-enol-pyruvate in the } \\
\text { presence of } 0.5 \mathrm{mM} \text { FDP } \\
(m M)\end{array}$ & 0.12 & $0.17 \pm 0.02(n=5)$ \\
\hline $\begin{array}{l}\text { Fructose-1,6-diphosphate } \\
\text { stimulation ( } \mu M \text { for } 50 \% \\
\text { activation) }\end{array}$ & $>20 \mu \mathrm{M}$ & $0.3-0.7 \mu \mathrm{M}$ \\
\hline$K_{\mathrm{m}} \operatorname{ADP}(m M)$ & 0.19 & $0.17 \pm 0.03(n=22)$ \\
\hline $\begin{array}{l}\text { ATP inhibition (\% activity at } 1 \\
\text { mM ATP in the presence } \\
\text { of } 0.5 \mathrm{mM} \text { P-enol- } \\
\text { pyruvate) }\end{array}$ & 113 & $(n=11)$ \\
\hline $\begin{array}{l}\text { Nucleotide specificity (\% of } \\
\text { activity with ADP) }\end{array}$ & & \\
\hline UDP & 44 & $55 \pm 9 \quad(n=21)$ \\
\hline Guanosine diphosphate & 60 & $63 \pm 7 \quad(n=21)$ \\
\hline Cytidine diphosphate & 9 & $8 \pm 3 \quad(n=6)$ \\
\hline $\begin{array}{l}\text { Thermostability, } \% \text { of remaining } \\
\text { activity after } 60 \mathrm{~min} \text { at } \\
54^{\circ} \mathrm{C}\end{array}$ & 81 & $71 \pm 13 \quad(n=18)$ \\
\hline pH curve (optimum) & 6.0 & $6.0-7.0$ \\
\hline $\begin{array}{l}\text { Electrophoresis } \\
\text { - Trypsin } \\
\text { + Trypsin }\end{array}$ & $\begin{array}{l}\text { normal } \\
\text { normal }\end{array}$ & $\begin{array}{l}\text { normal }\left(L_{2}^{\prime} L_{2}\right) \\
\text { normal }\left(L_{4}\right)\end{array}$ \\
\hline Immunological specific activity & normal & normal \\
\hline
\end{tabular}

glycolytic intermediates found in the erythrocytes of the patient described in this paper (Table IV) are in agreement with this hypothesis.

The HPLC analysis (Table V) shows that the high pyruvate kinase activity in the patient's erythrocytes increased the level of ATP without affecting the level of ADP or AMP. However, AMP is in the lower range, which might be a consequence of the cell's efforts to maintain equilibrium in the adenylate kinase reaction. Some "overflow" of high-energy phosphates into GTP and IMP was found.

It is well known that L-type pyruvate kinase from human erythrocytes shows allosteric properties (19). The kinetic behavior of pyruvate kinase can be explained by the $R \rightleftharpoons T$ model of Monod. In this model, the substrate phospho-enol-pyruvate, as well as Fru-1,6- $P_{2}$, cooperate in shifting the equilibrium towards the R-form, whereas the T-form is favored by ATP. The R form is catalytically more active than the T-form. The patient's enzyme reported here was characterized by an increase in the affinity for the substrate phospho-enol-pyruvate (the $K_{0.5}$ for this substrate is decreased more than sixfold compared with controls), whereas the enzyme was not inhibited by the negative effector ATP (under the conditions tested). This means a shift in the equilibrium to the $\mathrm{R}$ form in the Monod model. The decreased stimulation by Fru-1,6- $\mathrm{P}_{2}$ (Table VI) is in agreement with this assumption.

The shift in the equilibrium to the $\mathrm{R}$ form is not due to an increase of the Fru-1,6- $\mathrm{P}_{2}$ content because the level of this glycolytic intermediate was normal (Table IV). Under in vivo conditions (low phospho-enol-pyruvate, high ATP), pyruvate kinase with high affinity for phospho-enol-pyruvate and that is not inhibited by ATP should have a greater catalytic efficiency than controls. So, the hyperactivity of pyruvate kinase will be more pronounced in vivo than suggested by the elevated activity measured in vitro under optimal assay conditions.

Elder et al. (20) have described three cases of pyruvate kinase deficiency in which the common abnormality was a high affinity for phospho-enol-pyruvate. In contrast with our patient, the cases described by Elder et al. (20) showed severe hemolytic disease.

The hyperactivity of pyruvate kinase reported by Max-Audit et al. (8) and Rosa et al. (17) could be explained by the presence (besides the L-type) of the K-type in the patient's erythrocytes. The K-type is normally not present in the erythrocytes, but can be detected in earlier stages of erythroid differentiation $(21,22)$. The presence of pyruvate kinase type $\mathrm{K}$ in erythrocytes can be considered as a disorder of cell differentiation, as was proposed by Max-Audit et al. (8). In our case, no pyruvate kinase type $\mathrm{K}$ was detected in the erythrocytes; in the electrophoretic pattern, only the L-type was present. The pyruvate kinase activity in the patient's leukocytes was normal, indicating that the K-type isozyme is not affected by the inherited abnormality. The erythrocyte enzyme of our patient was further characterized by a normal $K_{\mathrm{m}}$ for ADP; the nucleotide specificity, the thermostability, and pH optimum were normal too. Finally, the immunological specific activity (defined as the number of enzyme units precipitated by $1 \mathrm{ml}$ of antiserum) was also shown to be normal. This finding suggests the possibility that the increase in pyruvate kinase activity (besides a shift in the Monod model to the more active $\mathrm{R}$ form) may also be due to an increase in enzyme synthesis or decreased degradation of the enzyme.

Recently, a mutant pyruvate kinase from Neurospora crassa with twice the activity of the wild type enzyme has been described (23). The mutant enzyme was characterized by an increased affinity for phospho-enol-pyruvate and normal kinetics with ADP. It was suggested that the increased degree of cooperativity towards this substrate can be ascribed to the structurally altered environment of the catalytic site, resulting in a more compact quaternary structure (23). The same could be valid for the enzyme described in this paper. It may also be possible that the patient is a heterozygote so that the abnormal kinetics are the result of the effect of the mutant enzyme in the presence of some level of normal enzyme.

In conclusion, the high pyruvate kinase activity found in the so-called "high ATP syndrome" may be based either on the presence of the K-type in addition to the L-type in the eryth- 
rocytes $(8,17)$, or alternatively, on a shift in the $R \rightleftharpoons T$ equilibrium to the $\mathrm{R}$-form together with an increased enzyme synthesis or decreased degradation (this paper). Because it is unlikely that two different mutations are present in the pyruvate kinase genes of our patient, we suggest that one mutation may have caused a structural change in the enzyme that leads both to a shift to the R-form and a decrease in the degradation.

\section{Acknowledgments}

We thank Dr. D. de Korte for the HPLC analysis, Dr. G. Rijksen and Dr. R. Oskam for helpful discussions, and Mrs. E. L. Huisman-Backer Dirks for typing the manuscript.

\section{References}

1. Ibsen, K. H. 1977. Interrelationships and functions of the pyruvate kinase isozymes and their variant forms: a review. Cancer Res. 37:341353.

2. Staal, G. E. J., G. Rijksen, A. M. C. Vlug, B. Vromen-van den Bos, J. W. N. Akkerman, G. Gorter, J. Dierick, and M. Petermans. 1982. Extreme deficiency of L-type pyruvate kinase with moderate clinical expression. Clin. Chim. Acta. 118:241-253.

3. Kahn, A., J. Marie, H. Garreau, and E. D. Sprengers. 1978. The genetic system of the L-type pyruvate kinase forms in man. Biochim. Biophys. Acta. 523:59-74.

4. Valentine, W. N., K. R. Tanaka, and S. Miwa. 1961. Specific erythrocyte glycolytic enzyme defect (pyruvate kinase) in three subjects with congenital non-spherocytic hemolytic anemia. Trans. Assoc. Am. Physicians. 74:100-110.

5. Brewer, G. J. 1964. A new inherited metabolic abnormality of human erythrocytes, characterized by elevated levels of adenosine-triphosphate (ATP). J. Clin. Invest. 43:1287. (Abstr.)

6. Brewer, G. J. 1965. A new inherited abnormality of human erythrocytes-elevated erythrocyte adenosine triphosphate. Biochem. Biophys. Res. Commun. 18:430-434.

7. Jacobasch, G., I. Syllm-Rapoport, H. Roigas, and S. Rapoport. 1964. 2,3-PGase Mangel als mögliche Ursach erhöhten ATP-Gehaltes. Clin. Chim. Acta. 10:477-478.

8. Max-Audit, J., R. Rosa, and J. Maree. 1980. Pyruvate kinase hyperactivity genetically determined: metabolic consequences and molecular characterization. Blood. 56:902-908.

9. Zürcher, C., J. A. Loos, and H. K. Prins. 1965. Hereditary high
ATP content of human erythrocytes. Bibl. Haematol. 23:549-556.

10. Minakami, S., C. Suzuki, T. Saito, and W. Yoshikawa. 1965. Studies on erythrocyte glycolysis. I. Determination of the glycolytic intermediates in human erythrocytes. J. Biochem. (Tokyo). 58:543-550.

11. Beutler, E., C. West, and K. G. Blume. 1976. The removal of leukocytes and platelets from whole blood. J. Lab. Clin. Invest. 88:328333.

12. Beutler, E. 1975. Red Cell Metabolism: A Manual of Biochemical Methods. Grune \& Stratton Inc., New York. Second ed. 38-71.

13. Miwa, S., P. Boivin, K. G. Blume, H. Arnold, J. A. Black, A. Kahn, G. E. J. Staal, K. Nakashima, K. R. Tanaka, D. E. Paglia, W. N. Valentine, A. Yoshida, and E. Beutler. 1971. Recommended methods for the characterization of red cell pyruvate kinase variants. Br. J. Haematol. 43:275-286.

14. McKeag, M., and P. R. Brown. 1978. Modification of highpressure liquid chromatographic nucleotide analysis. J. Chromatogr. 152:253-254.

15. Rennie, C. M., S. Thompson, A. C. Parker, and A. Maddy. 1979. Human erythrocyte fractionation in "Percoll" density gradients. Clin. Chim. Acta. 98:119-125.

16. Roos, D., R. S. Weening, A. A. Voetman, M. L. J. van Schaik, A. A. M. Bot, L. J. Meerhof, and J. A. Loos. 1979. Protection of phagocytic leukocytes by endogenous glutathione: studies in a family with glutathione reductase deficiency. Blood. 53:851-866.

17. Rosa, R., J. Max-Audit, V. Israel, Y. Benzerd, J. Thillet, and J. Rosa. 1981. Hereditary pyruvate kinase abnormalities associated with erythrocytosis. Am. J. Hematol. 10:47-55.

18. Jelkmann, W., and C. Bauer. 1980. Enzyme activities related to 2,3-P $\mathbf{P}_{2}$-glycerate metabolism in embryonic and fetal red cells. Biochem. Biophys. Res. Commun. 93:93-99.

19. Staal, G. E. J., J. F. Koster, H. Kamp, L. Van Milligen-Boersma, and C. Veeger. 1971. Human erythrocyte pyruvate kinase. Its purification and some properties. Biochim. Biophys. Acta. 227:86-96.

20. Elder, G. E., T. R. J. Lappin, B. E. Lawson, and J. M. Bridges. 1981. Three pyruvate kinase variants with increased affinity for PEP Br. J. Haematol. 47:371-381.

21. Takegawa, S., H. Fujii, and S. Miwa. 1983. Change of pyruvate kinase isozymes from $\mathrm{M}_{2}$ - to L-type during development of the red cell. Br. J. Haematol. 54:467-474.

22. Jansen, G., G. Rijksen, G. C. de Gast, and G. E. J. Staal. 1983. Glycolytic enzymes of an erythroleukemic cell line, K562, before and after hemoglobin induction. Exp. Hematol. (Lawrence). 11:626-638.

23. Yeung, M. C., and M. Kapoor. 1983. A study of the properties of pyruvate kinase isolated from a mutant of Neurospora crassa: a comparison with the parental enzyme. Int. J. Biochem. 15:523-529. 